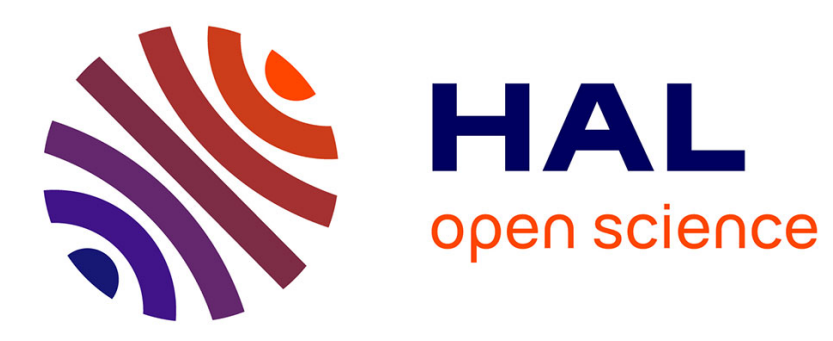

\title{
Strain-induced crystallization of carbon black-filled natural rubber during fatigue measured by in situ synchrotron X-ray diffraction
}

\author{
Stéphanie Beurrot, Bertrand Huneau, Erwan Verron, Pierre Rublon
}

\section{- To cite this version:}

Stéphanie Beurrot, Bertrand Huneau, Erwan Verron, Pierre Rublon. Strain-induced crystallization of carbon black-filled natural rubber during fatigue measured by in situ synchrotron X-ray diffraction. International Journal of Fatigue, 2013, 47, pp.1-7. 10.1016/j.ijfatigue.2012.07.001 • hal-01007325

\section{HAL Id: hal-01007325 \\ https://hal.science/hal-01007325}

Submitted on 11 Oct 2017

HAL is a multi-disciplinary open access archive for the deposit and dissemination of scientific research documents, whether they are published or not. The documents may come from teaching and research institutions in France or abroad, or from public or private research centers.
L'archive ouverte pluridisciplinaire HAL, est destinée au dépôt et à la diffusion de documents scientifiques de niveau recherche, publiés ou non, émanant des établissements d'enseignement et de recherche français ou étrangers, des laboratoires publics ou privés. 


\title{
Strain-induced crystallization of carbon black-filled natural rubber during fatigue measured by in situ synchrotron X-ray diffraction
}

\author{
S. Beurrot-Borgarino, B. Huneau*, E. Verron, P. Rublon \\ LUNAM Université, Ecole Centrale de Nantes, GeM, UMR CNRS 6183, BP 92101, 44321 Nantes cedex 3, France
}

\begin{abstract}
Natural rubber (NR) exhibits great fatigue properties which are usually explained by its ability to crystallize under strain. Nevertheless, strain-induced crystallization of NR in fatigue has never been investigated. We perform original in situ fatigue tests during which the degree of crystallinity, and the number and volume of crystallites are measured by synchrotron wide angle X-ray diffraction. For all loading conditions, the number of crystallites is constant. The evolution of their volume depends on the minimum stretch ratio achieved at each cycle. The results show that cyclic loading conditions modify the macromolecular structure of the material, in particular of its amorphous phase.
\end{abstract}

\author{
Keywords: \\ Rubber \\ Experimental technique \\ Strain-induced crystallization \\ Synchrotron WAXD
}

\section{Introduction}

Natural rubber (NR, cis-1,4-polyisoprene) vulcanizates have the ability to crystallize under strain at room temperature. Straininduced crystallization (SIC) of NR has been discovered by Katz in 1925 with the help of X-ray diffraction [1]. This technique has since permitted to obtain the crystallographic data of NR $[2,3]$, to exhibit the existence of stretch ratio thresholds of crystallization and melting of the crystallites [4,5], to relate SIC to the mechanical hysteresis of the stress-strain response [6,4], and to put into light the effect of fillers such as carbon black [7]. For more details on the use of X-ray diffraction for SIC in NR, the reader can refer to the recent review of Huneau [8].

The great majority of the studies on SIC of NR focus on uniaxial quasi-static cycles and relaxation tests. Here, the expression "quasistatic" stands for low strain rates compared to crystallization rate. But NR is often used in engineering applications for its great properties in fatigue such as long fatigue life, even at large strain [9-11]. The mechanical properties of NR have been thoroughly studied [12-14]; but studies on the evolution of SIC during fatigue testing of NR are very rare, though it is often accepted that the remarkable fatigue properties are closely related to SIC. This is mainly because the typical frequencies of fatigue tests ( $1 \mathrm{~Hz}$ or more) are not compatible with the long time acquisition required by X-ray diffraction measurements (from a few seconds to an hour). Nevertheless, Kawai succeeded in measuring SIC during fatigue by using a stroboscopic technique to accumulate the weak intensity of the

\footnotetext{
* Corresponding author. Tel.: +3324037 68 82; fax: +332 40372566 .

E-mail address: bertrand.huneau@ec-nantes.fr (B. Huneau).
}

diffracted beam over a large number of cycles [15]. He studied only one set of loading conditions for which both minimum and maximum stretch ratios achieved are 3.5 and 4.5 , respectively. In this case, he observed an increase in the degree of crystallinity with the number of cycles. Furthermore, Rouvière et al. recently measured the evolution of crystallinity along fatigue life for different uniaxial loading conditions by performing interrupted fatigue tests [16]. Nevertheless, this method does not allow to separate SIC induced by fatigue from SIC induced by constant stretching during the 45-min acquisition of the X-ray diffractogram.

The aim of the present study is to measure the evolution of the strain-induced crystallinity during fatigue of carbon black-filled NR and to determine the mechanisms that drive this evolution. For this purpose, we developed an innovative experimental method which allows to measure SIC in real time during a fatigue experiment. In-situ wide angle X-ray diffraction (WAXD) measurements are performed with a very short exposure time achieved thanks to synchrotron radiation. Thanks to the results obtained, we highlight the key role of the melting stretch ratio and we propose two mechanisms of SIC in NR fatigue depending on loading conditions.

\section{Experimental method}

\subsection{Material and samples}

The material used in this study is a carbon black-filled natural rubber, cross-linked with $1.2 \mathrm{phr}$ (per hundred of rubber) of sulphur and CBS accelerator. It also contains $\mathrm{ZnO}$ (5 phr) and stearic acid ( 2 phr) and is filled with 50 phr of N330 carbon black. The 


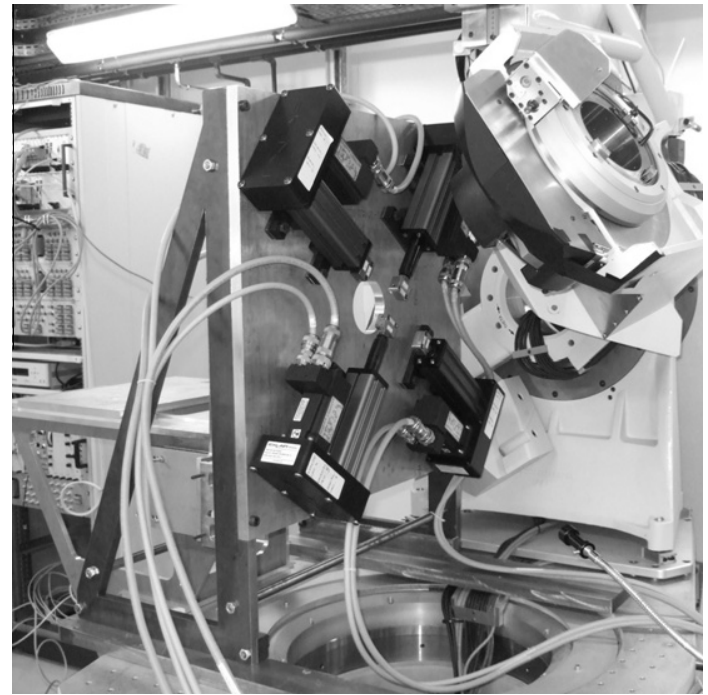

Fig. 1. Uniaxial fatigue machine in DiffAbs beamline.

samples are classical flat dumbbell specimen with a $10 \mathrm{~mm}$ gauge length and a $2 \times 4 \mathrm{~mm}^{2}$ section.

\subsection{Testing machine}

Experiments have been conducted with the homemade stretching machine shown in Fig. 1. It is composed of four electrical actuators, but only two opposite ones were used in this study. Their movements are synchronized, in order to keep the centre of the specimen fixed during the fatigue tests. Their loading capacity is $\pm 500 \mathrm{~N}$ and their stroke is $75 \mathrm{~mm}$ each.

\subsection{Procedures}

\subsubsection{Accommodation}

In order to lower the residual stretch ratio of the sample due to Mullins effect and viscoelasticity, all the samples are pre-cycled just before testing: 5 cycles at a higher strain level than during fatigue tests for Mullins effect (maximum displacement of the clamps is $45 \mathrm{~mm}$, except for fatigue test No. 4 described hereafter, before which the maximum displacement is $50 \mathrm{~mm}$ ); additional 50 cycles for viscous effect (at the same displacements of the clamps than during the fatigue tests).

\subsubsection{Preliminary quasi-static experiment}

A quasi-static test is beforehand conducted to determine (i) the relation between the stretch ratio $\lambda$ and the displacements of clamps which will be used in all other experiments and (ii) the stretch ratio thresholds of crystallization $\lambda_{C}$ and melting $\lambda_{M}$ of the material at room temperature and low strain rate (similarly as in [17]). During these experiments, the sample is elongated of $90 \mathrm{~mm}$ at the speed $0.012 \mathrm{~mm} \mathrm{~s}^{-1}$, the total duration of the cycle being about $2 \mathrm{~h}$. A scattering pattern is recorded every $98 \mathrm{~s}$. The local stretch ratio $\lambda$ at the centre of the sample is a posteriori measured continuously by video extensometry. Finally, this experiment is a quasi-static test from $\lambda=1$ to $\lambda=4$ at $\dot{\lambda}=1.1 \times 10^{-3} \mathrm{~s}^{-1}$, and it leads to $\lambda_{C}=2.36$ on the loading path and $\lambda_{M}=1.80$ on the unloading path.

\subsubsection{Fatigue experiments}

The fatigue tests are conducted by prescribing triangular displacements of the clamps. They are performed at conventional frequencies for rubber, i.e. around $1 \mathrm{~Hz}$, which limit self-heating
Table 1

Fatigue loading conditions.

\begin{tabular}{llllll}
\hline Test No. & $d_{\min }(\mathrm{mm})$ & $d_{\max }(\mathrm{mm})$ & $\lambda_{\min }$ & $\lambda_{\max }$ & $f(\mathrm{~Hz})$ \\
\hline 1 & 0 & 20 & 1.00 & 2.90 & 2.5 \\
2 & 4 & 33.2 & 1.44 & 3.66 & 0.8 \\
3 & 9.3 & 33.2 & 1.98 & 3.66 & 1 \\
4 & 25 & 45 & 3.18 & 4.02 & 1.5 \\
\hline
\end{tabular}

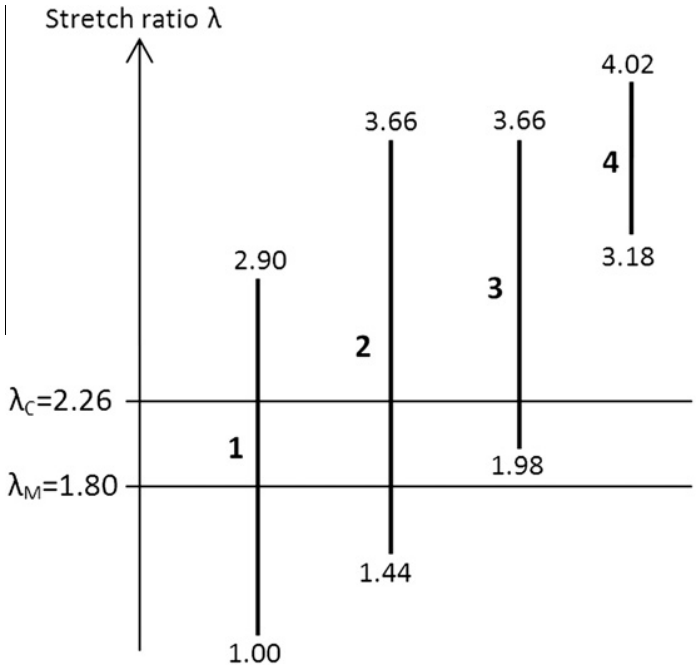

Fig. 2. Minimum and maximum stretch ratios reached during fatigue tests and threshold stretch ratios for crystallization $\lambda_{C}$ and melting $\lambda_{M}$. Bold numbers stand for the fatigue tests numbers.

to about $3^{\circ}$ only [18]. As the minimum exposure time to record a diffraction pattern is $1 \mathrm{~s}$ (about the duration of a full cycle), it is not possible to record the diffraction patterns while the actuators are in motion. Therefore, to measure the evolution of SIC during fatigue testing, the tests are paused at maximum displacement every 250 cycles to record a complete diffraction pattern. As the fatigue machine is triggered by the monitoring system of the X-ray beam, the duration of the pause is less than $1.5 \mathrm{~s}$. The first scattering pattern is recorded during the first cycle of the test.

Four different fatigue tests have been performed. Table 1 presents the corresponding minimum and maximum displacements of the clamps $d_{\min }$ and $d_{\max }$, the corresponding minimum and maximum stretch ratios $\lambda_{\min }$ and $\lambda_{\max }$ and the loading frequency $f$. To summarize the fatigue tests, Fig. 2 presents the loading conditions in terms of stretch ratios, and compares them to the thresholds of crystallization $\lambda_{C}$ and melting $\lambda_{M}$ (measured during the preliminary experiment).

\subsubsection{Relaxation experiments}

The relaxation tests consist in quickly stretching a sample to a given stretch ratio and then maintaining the same stretch level. They last $28 \mathrm{~min}$ and scattering patterns are recorded every $2 \mathrm{~min}$. Table 2 presents the stretch ratios at which the three relaxation experiments are conducted. The stretch rate $\dot{\lambda}$ of the loading path is between 5.6 and 6.0 for the three tests.

Table 2

Relaxation loading conditions.

\begin{tabular}{ll}
\hline Test No. & $\lambda$ \\
\hline 5 & 2.41 \\
6 & 2.90 \\
7 & 3.66 \\
\hline
\end{tabular}




\subsection{Synchrotron}

The synchrotron measurements have been carried out at the DiffAbs beamline in the French national synchrotron facility SOLEIL. The wavelength used is $1.319 \AA$ and the beam size is $0.3 \mathrm{~mm}$ in diameter at half-maximum. The 2D WAXD patterns are recorded by a MAR 345 CCD X-ray detector. The exposure time is $1 \mathrm{~s}$ (minimum time to record a workable scattering pattern) for the fatigue and relaxation tests. For the low strain rate cycle test, it is set to $2 \mathrm{~s}$ in order to enhance the accuracy of the measurements. A PIN-diode beam stop was used in order to make an accurate correction of air scattering.

\subsection{Scattering pattern analysis}

In this study, we consider large angle scattering: the range of diffraction angles is $2 \theta \in\left[8^{\circ}, 26.7^{\circ}\right]$. We used the $(012)$ reflections of $\mathrm{Cr}_{2} \mathrm{O}_{3}$ powder placed on each side of a specimen to calibrate the diffraction angles $2 \theta(a=4.9590 \AA$ and $c=1.3596 \AA)$. Moreover, we follow the well-established correction method of Ran et al. [19]: an

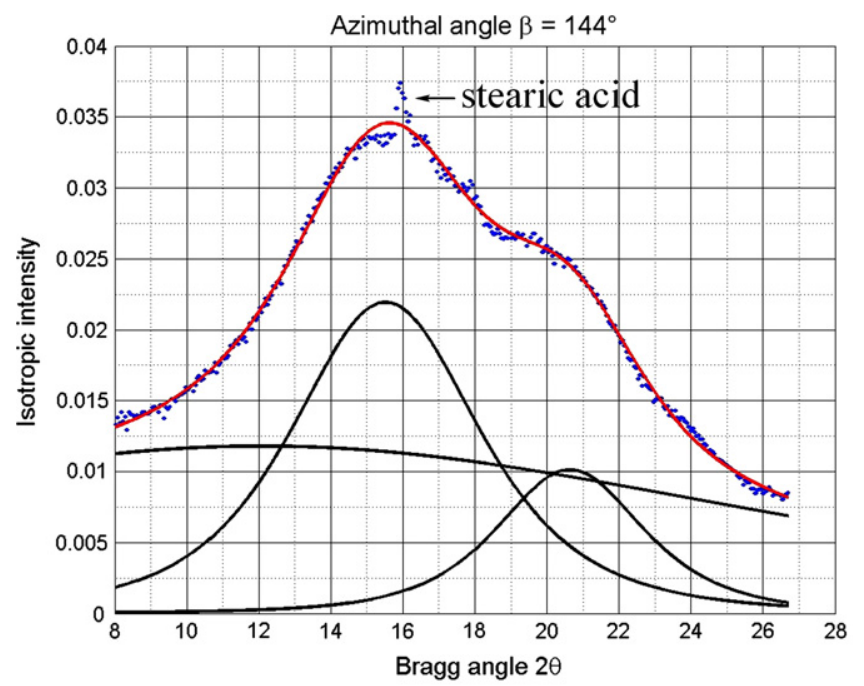

(a) $\left(2 \theta, I_{\text {iso }}\right)$

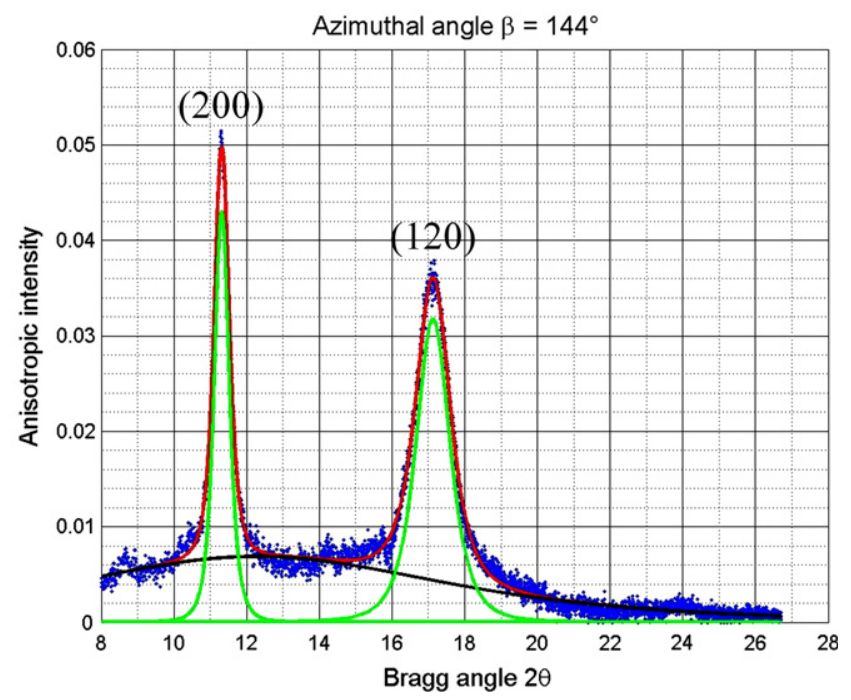

(b) $\left(2 \theta, I_{\text {ani }}\right)$

Fig. 3. Examples of deconvolution of diffraction diagrams fitted by series of Pearson functions. air scattering pattern (without sample) was first collected and has been used to correct the patterns, and the change in thickness of the sample under extension and the change in intensity of the incident photons have also been considered. Once the corrections performed, the intensity of photons diffracted by the isotropic phases in the material $I_{\text {iso }}(2 \theta)$ is extracted from the diffraction patterns by considering the minimum intensity along the azimuthal angle $\beta$ for each Bragg angle $2 \theta$. Then, the intensity of photons diffracted by the anisotropic material $I_{\text {ani }}(2 \theta, \beta)$ is calculated as the difference between the total intensity of photons diffracted $I_{\text {total }}(2 \theta, \beta)$ and $I_{\text {iso }}(2 \theta)$. The diffraction diagrams extracted from $I_{\text {ani }}(2 \theta, \beta)$ and $I_{\text {iso }}(2 \theta)$ are classically fitted by series of Pearson functions $[20,17,21,4]$. Figs. 3a and b present examples of fitting and deconvolution of diffraction diagrams $\left(2 \theta, I_{\mathrm{iso}}\right)$ and $\left(2 \theta, I_{\mathrm{ani}}\right)$ respectively. With these quantities, it is possible to calculate: an index of crystallinity, an index of the mean volume of crystallites, and an index of number of crystallites.

\subsubsection{Crystallinity}

The index of mass crystallinity $\chi$ is calculated as follow:

$\chi=\frac{\mathcal{I}_{\text {cryst }}}{\mathcal{I}_{\text {cryst }}+\mathcal{I}_{\text {amorph }}}$

where $\mathcal{I}_{\text {cryst }}$ is the integrated intensity of the (120) and (200) Bragg reflections of NR measured on one diffraction diagram $\left(2 \theta, I_{\mathrm{ani}}\right)$ and $\mathcal{I}_{\text {amorph }}$ is the integrated intensity of the amorphous halo at the same diffraction angle, assumed equal to the integrated intensity $I_{\text {iso }}$.

\subsubsection{Mean volume of crystallites}

An index of the mean volume of the crystallites $\bar{V}_{\text {cryst }}$ is calculated from the crystallites size in three different directions:

$\bar{V}_{\text {cryst }}=l_{200} \cdot l_{120} \cdot l_{201}$

where the mean crystallites size $l_{h k l}$ is deduced from the Scherrer formula [22]:

$$
l_{h k l}=\frac{K \lambda}{\text { FWHM }_{2 \theta} \cos \theta}
$$

in which $l_{h k l}$ is the crystallites size in the direction normal to the $h k l$ diffraction plane, $K$ is a scalar which depends on the shape of the crystallites (here we adopt 0.78 as in [17]), $\lambda$ is the radiation wavelength, $\theta$ is the Bragg angle and $\mathrm{FWHM}_{2 \theta}$ is the full width at halfmaximum of the peak $h k l$ in a diffraction diagram $\left(2 \theta, I_{\mathrm{ani}}\right)$.

\subsubsection{Number of crystallites}

Assuming the incompressibility of the material and that the volume crystallinity is equal to the mass crystallinity, we calculate an index of number of crystallites per unit of undeformed volume $N_{\text {cryst }}$ :

$N_{\text {cryst }}=\frac{\chi}{\bar{V}_{\text {cryst }}} V_{\text {irradiated. }}=\frac{\chi}{\bar{V}_{\text {cryst }}} \frac{\pi R^{2} t_{0}}{\sqrt{\lambda}}$

where $V_{\text {irradiated }}$ is the volume irradiated by the X-ray beam, $R$ is the radius at half-maximum of the beam, $t_{0}$ is the thickness of the sample in the undeformed state and $\lambda$ is the stretch ratio.

\section{Results and discussion}

\subsection{Evolution of crystallinity during fatigue tests}

The evolution of the index of crystallinity (measured at maximum deformation) during fatigue tests for different strain levels is shown in Fig. 4.

As expected, larger is the strain, higher is the crystallinity. During the three fatigue tests with the lowest minimum and 


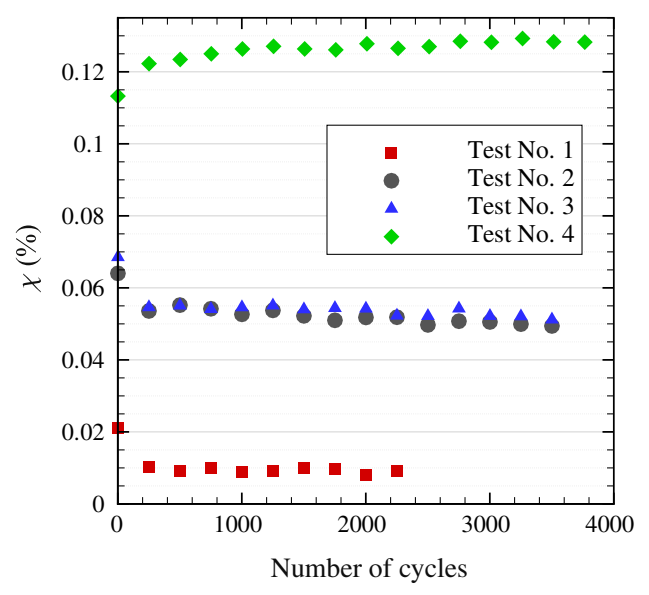

(a) During the first 4,000 cycles.

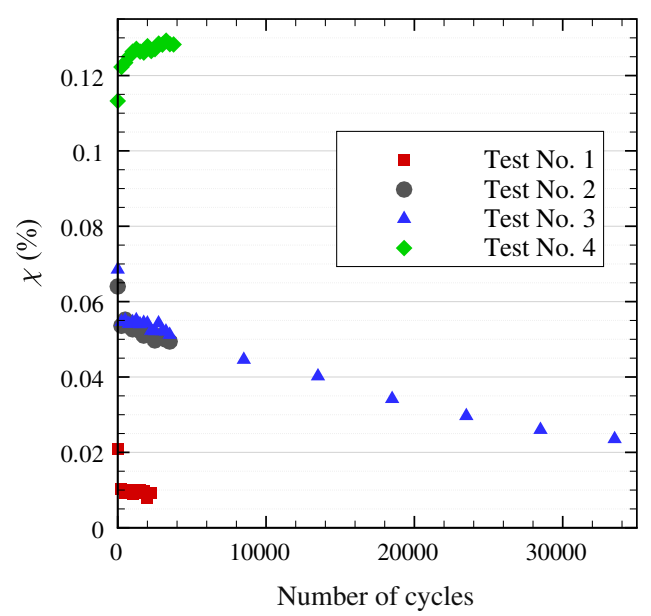

(b) During the first 35,000 cycles of test No. 3 .

Fig. 4. Evolution of the crystallinity index during fatigue tests.

maximum strain levels (tests No. 1, 2 and 3), the index of crystallinity decreases (of 15-50\%) during the first 250 cycles, and then continues to decrease at a lower but constant rate until the end of the tests. During fatigue test No. 4 , which minimum and maximum strain levels are much higher (see Fig. 2), the evolution of the index of crystallinity is very different: $\chi$ increases with the number of cycles (of about 13\% during the first 4000 cycles). This result is in agreement with those of Kawai [15] obtained during a fatigue test at $\lambda_{\min }=3.5$ and $\lambda_{\max }=4.5$. It is to note that the results shown in Fig. 4a only correspond to the first 4000 cycles, but fatigue test No. 3 was performed during 35,000 cycles as shown in Fig. $4 \mathrm{~b}$ and we observe that $\chi$ decreases at a constant rate during the whole test, down to about $\chi=2 \%$ in comparison with $\chi=7 \%$ at the beginning of the test.

As mentioned above, the fatigue tests were performed by prescribing constant maximum and minimum displacements of the clamps. As the material is cycled, the strain level reached at a given displacement of each cycle decreases, because the reference length of the sample at zero-stress increases with the number of cycles due to Mullins and viscous effects. This phenomenon is reduced by the accommodation of the material, but it cannot be completely suppressed. Thus, all results of the fatigue tests are obtained for a constant maximum displacement which corresponds to a decreasing maximum strain level. As shown in Fig. 2, fatigue tests No. 1 and 2 are performed with minimum stretch ratios lower than $\lambda_{M}$.

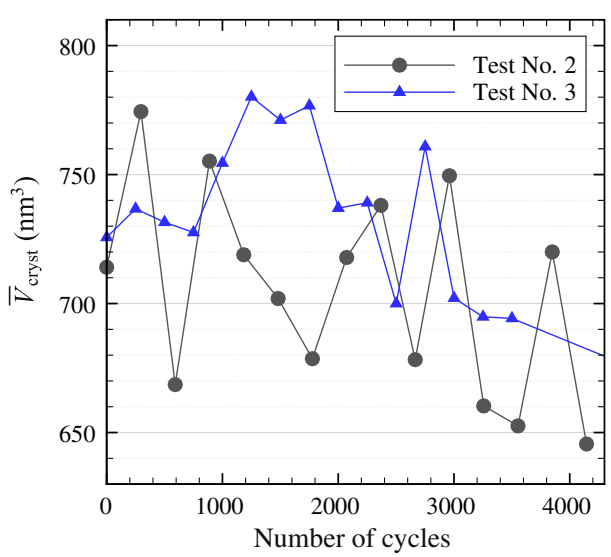

(a) Volume of the crystallites

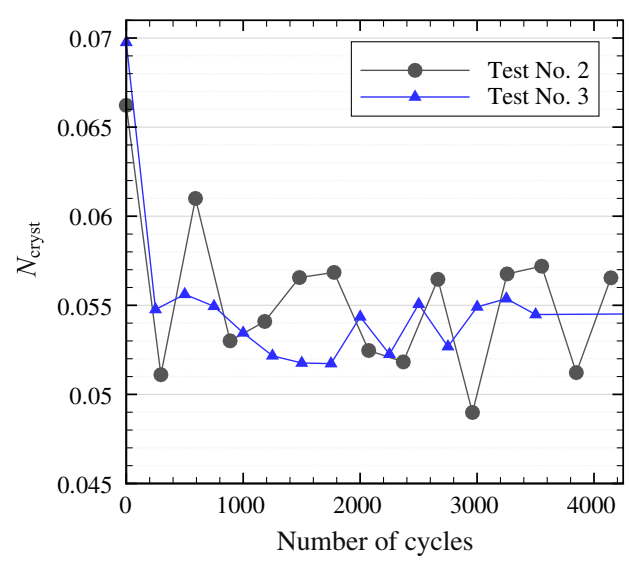

(b) Number of crystallites

Fig. 5. Evolution of the crystallites during fatigue tests No. 2 and 3.

Moreover, even if the initial minimum stretch ratio in the fatigue test No. 3 is slightly higher than $\lambda_{M}$, it becomes lower after a few cycles only. So, for these three tests, the same phenomenon takes place during each cycle: all the crystallites melt when the minimum displacement is reached, and new crystallites nucleate when the sample is stretched again; and $\chi$ decreases with the number of cycles. For fatigue test No. 4 , the minimum stretch ratio reached at each cycle decreases with the number of cycles as well, but it is always greatly larger than the threshold of crystallization $\lambda_{C}$, and then than the threshold of melting $\lambda_{M}$.

Finally, three cases can be highlighted:

- The maximum stretch ratio in one cycle $\lambda_{\max }$ is lower than the threshold of crystallization $\lambda_{c}: \chi$ remains equal to 0 .

- $\lambda_{\max }$ is higher than $\lambda_{c}$ and the minimum stretch ratio in one cycle $\lambda_{\text {min }}$ is lower than the threshold of melting $\lambda_{M}$ : all crystallites melt at each cycle and the maximum crystallinity index decreases with the number of cycles. This is the case of tests No. 1, 2 and 3.

- $\lambda_{\max }$ is higher than $\lambda_{C}$ and $\lambda_{\min }$ is higher than $\lambda_{M}$. During the cycles, some crystallites never melt: the maximum crystallinity index reached in each cycle increases with the number of cycles. This is the case of the test No. 4.

As the change in crystallinity can be induced by the change in the mean number of crystallites and/or the change in the mean volume of crystallites, the two latter aforementioned cases will be analyzed in terms of these quantities. 


\section{2. $\lambda_{\max }>\lambda_{C}$ and $\lambda_{\min }<\lambda_{M}$ : Tests No. 2 and 3}

In this section, only tests No. 2 and 3 are considered because the diffraction diagrams for test No. 1 are too noisy to be analyzed due to a very small degree of crystallinity. Similarly, only the first 14,000 cycles of test No. 3 are considered. The evolution of the mean volume of the crystallites and of the number of crystallites is shown in Fig. 5a and b respectively. It shows that the mean volume of crystallites decreases continuously with the number of cycles. Their number decreases during the first 250 cycles, and is then constant. We observe the same evolution of both quantities for higher number of cycles as illustrated by the results for fatigue test No. 3 given in Fig. 6. Thus, the decrease in crystallinity shown in Fig. 4 is due to the simultaneous decrease in volume and number of crystallites at the beginning of the tests ( 250 cycles), and only to the decrease in size for further cycles. Recalling that all crystallites melt at the end of each cycle, it means that at each cycle the newly nucleated crystallites are smaller than the ones nucleated and melted during the previous cycle. It is to note that the decrease of $\bar{V}_{\text {cryst }}$ with the number of cycles is not explained by the decrease of $\lambda_{\max }$. Indeed, during quasi-static tests the lower the strain, the higher the size of the crystallites as shown in [17,23-26]; similar results have been obtained for strain rates similar to those of the present fatigue tests [27]. Moreover, results are the same for tests No. 2 and 3 which are performed at the same maximum stretch ratio $\lambda_{\max }>\lambda_{C}$ but two different minimum stretch ratios $\lambda_{\min }<\lambda_{M}$. Then, it suggests that when the minimum stretch ratio is smaller than the threshold of melting, the value of this minimum stretch ratio does not influence how the material crystallizes at minimum deformation.

As a summary: (i) $\bar{V}_{\text {cryst }}$ and $\chi$ depend on the number of cycles and (ii) $N_{\text {cryst }}, \bar{V}_{\text {cryst }}$ and $\chi$ at $\lambda_{\max }$ do not depend on $\lambda_{\min }$ when inferior to $\lambda_{M}$. These observations can be interpreted in the following way:

- The mechanical loading history has no effect on the material for strain smaller than $\lambda_{M}$.

- The mechanical loading history modifies the material for strain larger than $\lambda_{c}$. Indeed, as the crystallites evolve in time for the same loading conditions, it indicates that the macromolecular structure of the material changes from one cycle to another.

- Our experiments show that the crystalline phase of NR is different from one cycle to another, eventhough the mechanical conditions are similar; at each cycle, the crystalline phase totally

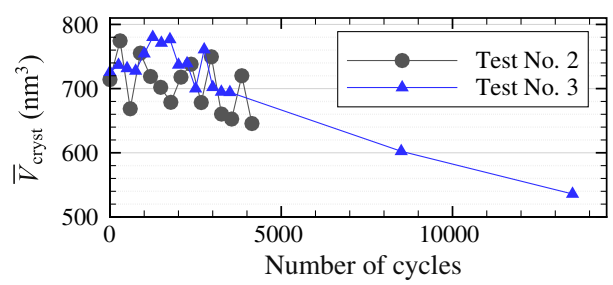

(a) Volume of the crystallites

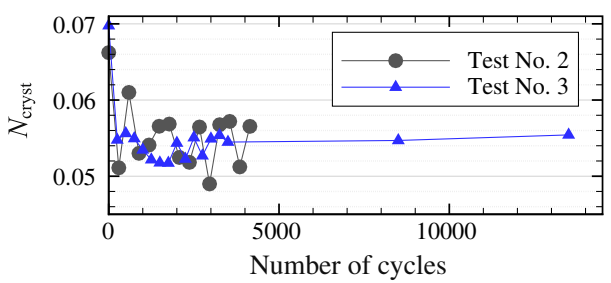

(b) Number of crystallites

Fig. 6. Evolution of the crystallites during fatigue test No. 2 and the 14,000 first cycles of fatigue test No. 3. melts and reappears differently at the next cycle. Thus, it suggests that the amorphous macromolecular structure of the material changes along fatigue testing.

\section{3. $\lambda_{\max }>\lambda_{C}$ and $\lambda_{\min }>\lambda_{M}$ : Test No. 4}

During fatigue test No. 4 , for which the stretch ratio always remains greater than $\lambda_{c}$, the crystallinity index increases with the

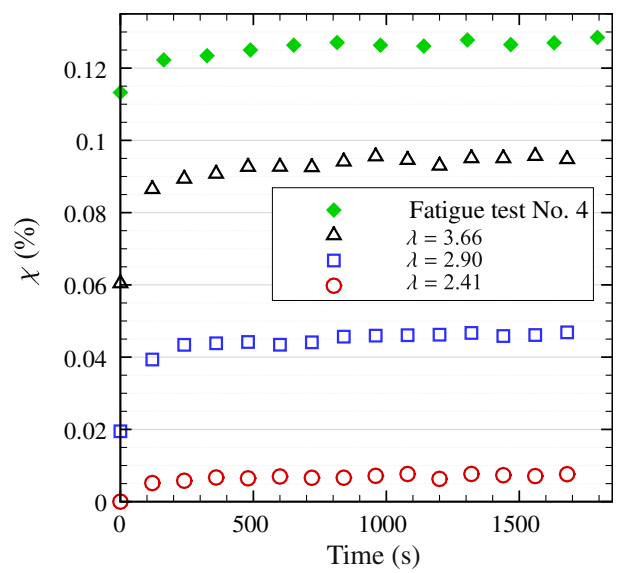

Fig. 7. Evolution of the crystallinity index $\chi$ with time during fatigue test No. 4 and relaxation tests. The stretch ratios $\lambda$ at which the relaxation tests are performed are given in the legend.

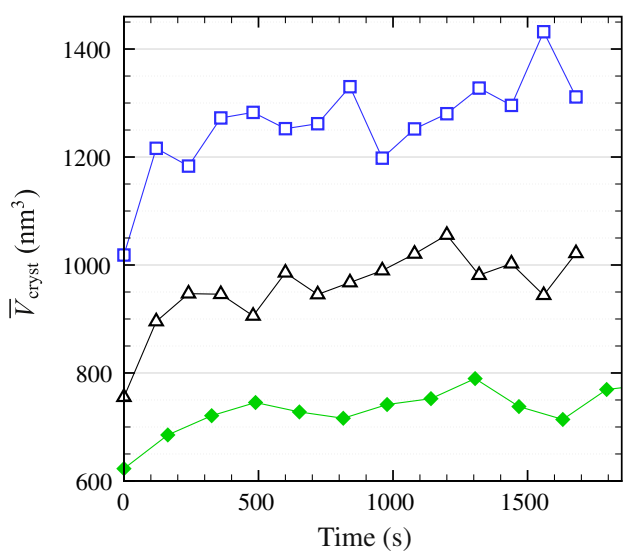

(a) Volume of crystallites (see (b) for legend).

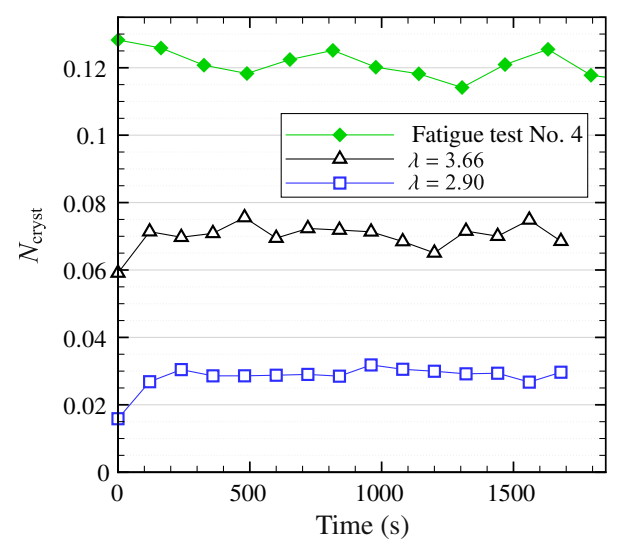

(b) Number of crystallites.

Fig. 8. Evolution of the crystallites during fatigue test No. 4 and relaxation tests. Legends of (a) and (b) are the same and only given in (b) for clarity. The stretch ratios $\lambda$ at which the relaxation tests are performed are given in the legend. 
number of cycles. Yet, it is well-established that crystallinity increases as well during relaxation experiments when the stretch ratio is higher than $\lambda_{C}[28,29]$. One can wonder whether the increase of crystallinity during fatigue is related to its evolution during relaxation, and in which ways. On this purpose the relaxation experiments described in Section 2.3.4 are conducted. Fig. 7 presents the evolution of the index of crystallinity in time for the fatigue test No. 4 and relaxation experiments. As expected, $\chi$ increases during relaxation because the stretch ratio is maintained higher than the threshold of crystallization $\lambda_{C}$ and the equilibrium state is very long to achieve.

Fig. 8 presents the evolution of the volume of the crystallites and their number for both test No. 4 and two relaxation tests. Quantitatively, both volumes and numbers highly differ from one test to another. These differences are due to the values of $\lambda_{\max }$ for each test: the higher the stretch ratio, the smaller and the more numerous the crystallites, as exhibited in [23,25]. For all the tests, the volume increases in time, and this increase is higher during relaxation than during fatigue (about $+20 \%$ for fatigue test and $+33 \%$ for both relaxation tests). Moreover, the number of

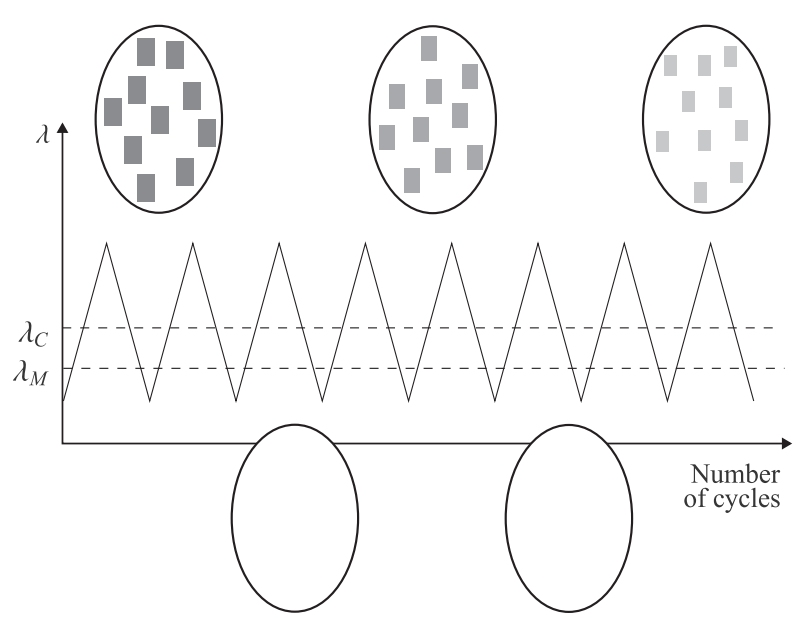

(a) $\lambda_{\min }<\lambda_{M}$

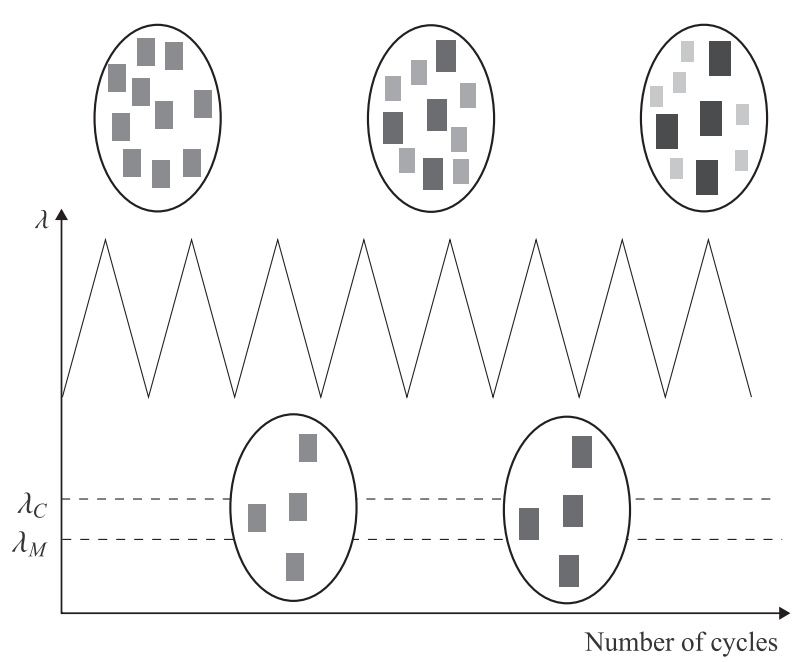

(b) $\lambda_{\min }>\lambda_{M}$

Fig. 9. Scenario of crystallization under different fatigue loading conditions. The ovals stand for a unit volume of material. The ones at the top of the figures represent the material at maximum strain whereas the ones at the bottom represent the material at minimum strain. The grey rectangles stand for the crystallites and the larger the crystallite, the larger and darker the rectangle. crystallites seems to be constant for the fatigue test whereas it slightly increases at the beginning of the relaxation tests then remains constant.

During the fatigue test No. 4 , because the stretch ratio is always larger than $\lambda_{M}$ we think that the most probable scenario is as follow. Two families of crystallites coexist, and at each cycle:

- some crystallites do not melt. They evolve during the whole fatigue test as crystallites in NR subjected to relaxation: their volume increases in time,

- the other crystallites disappear; new ones will nucleate during the next cycle. Those crystallites behave as during fatigue tests No. 2 and 3: their volume decreases from one cycle to another.

The sum of the number of crystallites of both families is constant. As shown in Figs. 5 and 8 the increase in volume during relaxation is higher of more than one decade than the decrease in volume during fatigue tests No. 2 and 3. Assuming that the change in crystallites volume of each family follows the same trend as for relaxation and fatigue tests No. 2 and 3, respectively, the mean volume of crystallites increases during fatigue test No. 4 and then it explains the increase of crystallinity during this test. It must be noted that as in fatigue tests No. 2 and 3, the macromolecular structure of the material (including of the amorphous phase) is modified in time during test No. 4 and then some crystallites which did not melt during a large number of cycles may eventually melt because of the evolution of the mechanical state of the neighbouring macromolecules. Similarly, some crystallites may nucleate after a large number of cycles and not melt afterwards.

\section{Conclusion}

In this study, we developed an original experimental method to measure in real time the evolution of strain-induced crystallization of NR during fatigue by in situ synchrotron WAXD. The main results are twofold. First, the number of crystallites per unit volume measured at maximum strain is constant during fatigue. Second, the minimum stretch ratio reached at each cycle $\lambda_{\min }$ as compared to the threshold of melting $\lambda_{M}$ drives the evolution of the mean volume of crystallites and therefore of the degree of crystallinity: if $\lambda_{\min }<\lambda_{M}$ the mean volume and the crystallinity decrease with the number of cycles, whereas if $\lambda_{\min }>\lambda_{M}$ they increase.

To explain those results, we propose the crystallization scenario detailed in Section 3; a simplified scenario, which shows only the main phenomena occurring during fatigue, is summarized in Fig. 9. We believe that this unexpected behaviour may be due to a modification of the macromolecular structure of the material, and especially of its amorphous phase, induced by cyclic loading conditions. The origin of this modification is not clarified yet: does the strain-induced crystallization change the macromolecular structure of the amorphous phase? If yes, does it explain the great fatigue strength of crystallizable elastomers $[9,30,10,31]$ ?

\section{Acknowledgments}

The authors thank Dr. D. Thiaudière, Dr. C. Mocuta and Dr. A. Zozulya from the DiffAbs beamline in Soleil synchrotron facility for their great help during the experiments.

\section{References}

[1] Katz JR. Rontgen spectographic testings on expanded rubber and its possible relevance for the problem of the extension characteristics of this substance. Naturwissenschaften 1925;13:410-6.

[2] Bunn CW. Molecular structure and rubber-like elasticity I. The crystal structures of beta gutta-percha, rubber and polychloroprene. Proc Royal Soc Lond Se A - Math Phys Sci 1942;180(A980):40-66. 
[3] Nyburg SC. A statistical structure for crystalline rubber. Acta Crystallogr 1954;7(5):385-92.

[4] Toki S, Fujimaki T, Okuyama M. Strain-induced crystallization of natural rubber as detected real-time by wide-angle X-ray diffraction technique. Polymer 2000;41:5423-9.

[5] Trabelsi S, Albouy PA, Rault J. Stress-induced crystallization around a crack tip in natural rubber. Macromolecules 2002;35(27):10054-61.

[6] Clark GL, Le Tourneau RL, Ball JM. Hysteresis in the crystallization of stretched vulcanized rubber II. X-ray studies of the effects of sulfur content and method of curing. Rubber Chem Technol 1941;14:546-54.

[7] Lee DJ, Donovan JA. Microstructural changes in the crack tip region of carbon black-filled natural rubber. Rubber Chem Technol 1987;60:910-23.

[8] Huneau B. Strain-induced crystallization of natural rubber: a review of X-ray diffraction investigations. Rubber Chem Technol 2011;84:425-52.

[9] Cadwell SM, Merril RA, Sloman CM, Yost FL. Dynamic fatigue life of rubber. Ind Eng Chem 1940;12:19-23.

[10] André N, Cailletaud G, Piques R. Haigh diagram for fatigue crack initiation prediction of natural rubber components. Kaut Gummi Kunstst 1999;52: 120-3.

[11] Saintier N, Cailletaud G, Piques R. Multiaxial fatigue life prediction for a natural rubber. Int J Fatigue 2006;28:530-9.

[12] Mars WV, Fatemi A. A literature survey on fatigue analysis approaches for rubber. Int J Fatigue 2002;24:949-61.

[13] Legorju-jago K, Bathias C. Fatigue initiation and propagation in natural and synthetic rubbers. Int J Fatigue 2002;24:85-92.

[14] Le Saux V, Marco Y, Calloch S, Doudard C, Charrier P. Fast evaluation of the fatigue lifetime of rubber-like materials based on a heat build-up protocol and micro-tomography measurements. Int J Fatigue 2010;32(10):1582-90.

[15] Kawai H. Dynamic X-ray diffraction technique for measuring rheo-optical properties of crystalline polymeric materials. Rheol Acta 1975;14:27-47.

[16] Rouvière JY, Bennani A, Pachoutinsky D, Besson J, Cantournet S. Influence of mechanical and fatigue loading on crystallization of carbon black-filled natural rubber. In: Taylor, Francis P, editors. Constitutive models for rubber V, Paris; 2007. p. 323-6.

[17] Trabelsi S, Albouy PA, Rault J. Crystallization and melting processes in vulcanized stretched natural rubber. Macromolecules 2003;36(20):7624-39.
[18] Candau N, Chazeau L, Chenal JM, Gauthier C, Ferreira J, Munch E, et al. Characteristic time of strain induced crystallization of crosslinked natural rubber. Polymer 2012;53:2540-3.

[19] Ran S, Fang D, Zong X, Hsiao BS, Chu B, Cunniff PF. Structural changes during deformation of Kevlar fibers via on-line synchrotron SAXS/WAXD techniques. Polymer 2001;42(4):1601-12.

[20] Chenal JM, Gauthier C, Chazeau L, Guy L, Bomal Y. Parameters governing strain induced crystallization in filled natural rubber. Polymer 2007;48(23): 6893-901.

[21] Rault J, Marchal J, Judeinstein P, Albouy PA. Chain orientation in natural rubber, part II: 2H-NMR study. Euro Phys J E 2006;21:243-61.

[22] Guinier A. X-ray diffraction. W.H. Freeman \& Co; 1963.

[23] Trabelsi S, Albouy PA, Rault J. Effective local deformation in stretched filled rubber. Macromolecules 2003;36(24):9093-9.

[24] Tosaka M, Murakami S, Poompradub S, Kohjiya S, Ikeda Y, Toki S, et al. Orientation and crystallization of natural rubber network as revealed by WAXD using synchrotron radiation. Macromolecules 2004;37:3299-309.

[25] Poompradub S, Tosaka M, Kohjiya S, Ikeda Y, Toki S, Sics I, et al. Mechanism of strain-induced crystallization in filled and unfilled natural rubber vulcanizates. J Appl Phys 2005;97(10):103529/1-9/9.

[26] Tosaka M. Strain-induced crystallization of crosslinked natural rubber as revealed by X-ray diffraction using synchrotron radiation. Polymer J 2007;39:1207-20.

[27] Beurrot-Borgarino S. Cristallisation sous contrainte du caoutchouc naturel en fatigue et sous sollicitation multiaxiale. Ph.D. Thesis; Ecole Centrale de Nantes; 2012.

[28] Treloar LRG. Crystallization phenomena in raw rubber. Trans Faraday Soc 1941;37(238):84-97.

[29] Komura M, Nakajima K, Nishi T, Ikehara T, Zhaobin Q. Pulsed NMR studies on long-term crystallization behavior and melting process of natural rubber under elongation. Rubber Chem Technol 2008;81(1):110-20.

[30] Lake GJ. Fatigue and fracture of elastomers. Rubber Chem Technol 1995;68:435-60.

[31] Saintier N, Cailletaud G, Piques R. Cyclic loadings and crystallization of natural rubber: an explanation of fatigue crack propagation reinforcement under a positive loading ratio. Mater Sci Eng A 2010;528(3):1078-86. 